\title{
Sustaining education in the age of COVID-19: a survey of synchronous web-based platforms
}

\author{
Jai Sidpra $^{1}$, Celia Gaier ${ }^{1}$, Nihaal Reddy ${ }^{2}$, Neetu Kumar ${ }^{3}$, David Mirsky $^{4}$, Kshitij Mankad ${ }^{5} \wedge$ \\ ${ }^{1}$ University College London Medical School, London, UK; ${ }^{2}$ Department of Radiology, Rainbow Children's Hospital and Tenet Diagnostics, \\ Hyderabad, India; ${ }^{3}$ Department of Urology, Great Ormond Street Hospital, London, UK; ${ }^{4}$ Department of Radiology, Children's Hospital Colorado, \\ University of Colorado School of Medicine, Aurora, Colorado, USA; ${ }^{5}$ Department of Radiology, Great Ormond Street Hospital, London, UK
}

Correspondence to: Dr. Kshitij Mankad. Department of Radiology, Great Ormond Street Hospital, London, UK. Email: drmankad@gmail.com.

Provenance and Peer Review: This article was commissioned by the editorial office, Quantitative Imaging in Medicine and Surgery. The article did not undergo external peer review.

Submitted May 29, 2020. Accepted for publication Jun 28, 2020.

doi: 10.21037/qims-20-714

View this article at: http://dx.doi.org/10.21037/qims-20-714

The ongoing severe acute respiratory syndrome coronavirus 2 (SARS-CoV-2) pandemic and the associated coronavirus disease 2019 (COVID-19) have had profound global and personal implications, with 5,701,337 confirmed cases and 357,688 confirmed deaths across 213 countries, areas, and territories at the time of writing (1). A concerted international response to the outbreak has focused on social distancing and quarantine measures through the closure of schools, workplaces, and community centers, in addition to household isolation, as a means of limiting humanto-human transmission and disease progression, thereby reducing the strain on the healthcare system. The novelty of the virus accompanied by its asymptomatic transmission and lack of a current treatment or vaccine highlights the importance of self-isolation to reduce global infection rates (2-4). Such techniques for the control of communicable diseases are not novel and have been successfully employed in previous outbreaks, notably the $1918 \mathrm{H} 1 \mathrm{~N} 1$ pandemic and the 2003 SARS pandemic (5-8). Their efficacy has not only been shown in clinical studies but also in simulations and pandemic models $(9,10)$. A modelling study conducted by Prem et al. investigated the efficacy of social distancing on the current SARS-CoV-2 pandemic and determined a projective reduction in median infection rates of $24 \%$ by the end of 2020 following a staggered return to work commencing at the beginning of April 2020 (11).

Despite the demonstrated efficacy of social distancing measures, their use imposes significant economic costs and psychosocial challenges $(8,12)$. Of significant concern is the disruption to education and training, with The United Nations Educational, Scientific and Cultural Organization estimating that $87.6 \%$ of enrolled learners have been affected by the pandemic (13). Many institutions, including our own, are turning to online teaching and educational platforms, many of which rely on synchronous videoconferencing (14). Due to the nature of medicine and the need to maintain the standard of patient care, maintaining the integrity and continuity of medical teaching is paramount when possible (15). We posit that videoconferencing tools are part of the solution towards this goal through their provision of educational content to students globally.

Videoconferencing is defined as "a conference in which participants in different locations are able to communicate with each other with both sound and vision" (16). This broader term encapsulates both meetings and web-based seminars (also known as webinars). The authors aim to mitigate the disruption of the current SARS-CoV-2

^ORCID ID for Jai Sidpra: 0000-0003-1985-5503; ORCID ID for Kshitij Mankad: 0000-0001-5979-9337. 


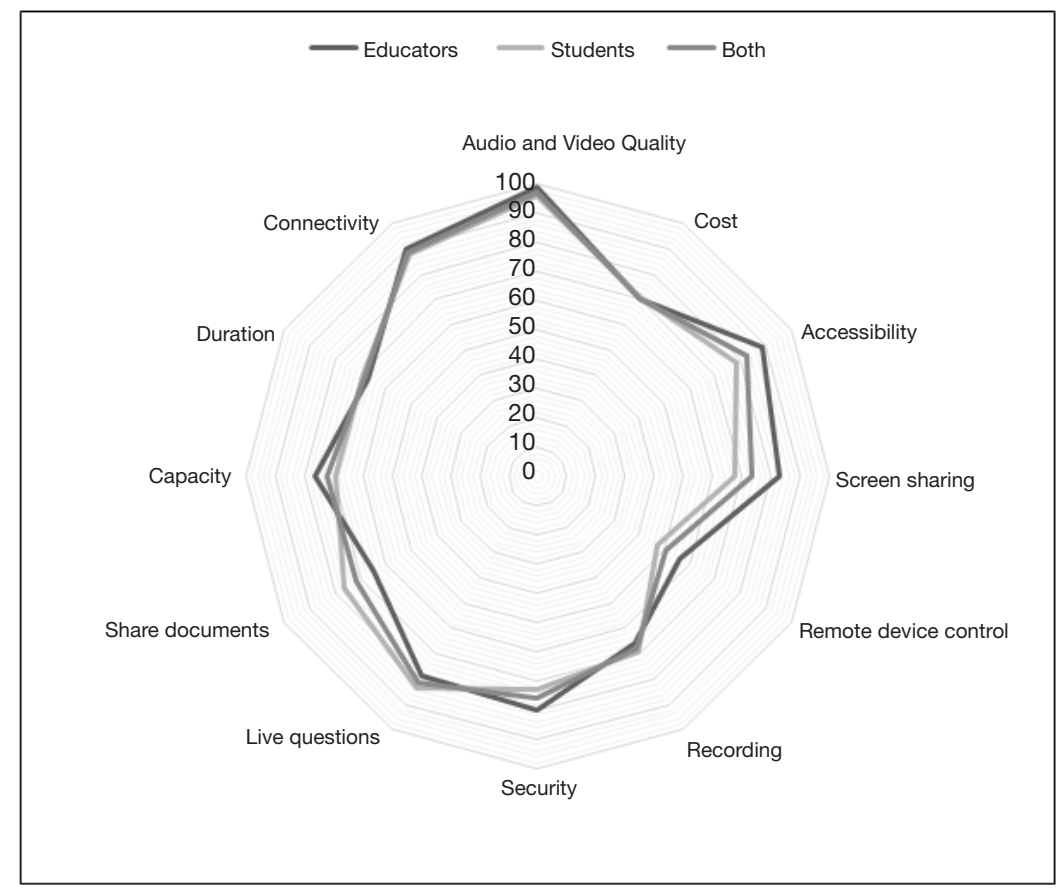

Figure 1 A radar plot showing the importance of different factors associated with videoconferencing tools.

pandemic on medical education by reviewing the available videoconferencing platforms and suggesting those most suited to educational use based on a set criterion as derived from a surveyed cohort of medical students and educators. By doing so, we aim to ease the transition from face-to-face to online teaching.

We evaluated 50 commonly used web-based videoconferencing platforms and selected the most suitable platforms from these based on core criteria of cost per month, capacity, accessibility, security, and minimum conference duration.

These criteria were based on the most important factors affecting the delivery of teaching via synchronous videoconferencing as determined by an international population of 30 surveyed medical students and 20 surveyed medical educators. The survey participants were asked whether they had used videoconferencing tools before, and if so, what they were; which criteria would be the most important for them when using such a platform; and the medical fields that they thought would be most suitable for teaching via videoconferencing. We also informed our criteria-namely those of cost, safety, equity, feasibility, and efficacy - from those of the standard health technology assessment (17).

We divided the platforms which fit these criteria into those best suited to smaller, seminar-based teaching and those best suited to larger, lecture-based teaching. In terms of the smaller, seminar-based teaching, our selection criteria were a maximum of $\$ 50$ per month for a minimum of 50 people, Microsoft, iOS, Android and Linux compatibility, end-to-end encryption, and a minimum of 2 hours per meeting. In contrast, the criteria for larger, lecture-based teaching was $\$ 75$ per month with a minimum of 250 people, while keeping accessibility and safety criteria identical to both teaching methods.

Data collected from the survey of 50 medical students and educators shows that $92 \%$ had previously used an online, synchronous videoconferencing platform for teaching, and that $88 \%$ of those who had done so are comfortable with using them. Of the live platforms that the participants had already used, the three most commonly used were GoToMeeting, Skype, and Zoom. As can be seen in Figure 1,97\% determined audio and video quality to be the most important factor on average, whilst $57 \%$ said remote device control was the least important factor in determining the videoconferencing platform that they were most likely to use. Other factors judged to carry importance include screen sharing, speaker and organizer controls, background image quality, as well as the ability to have multiple hosts. It is important to note that one of the areas 


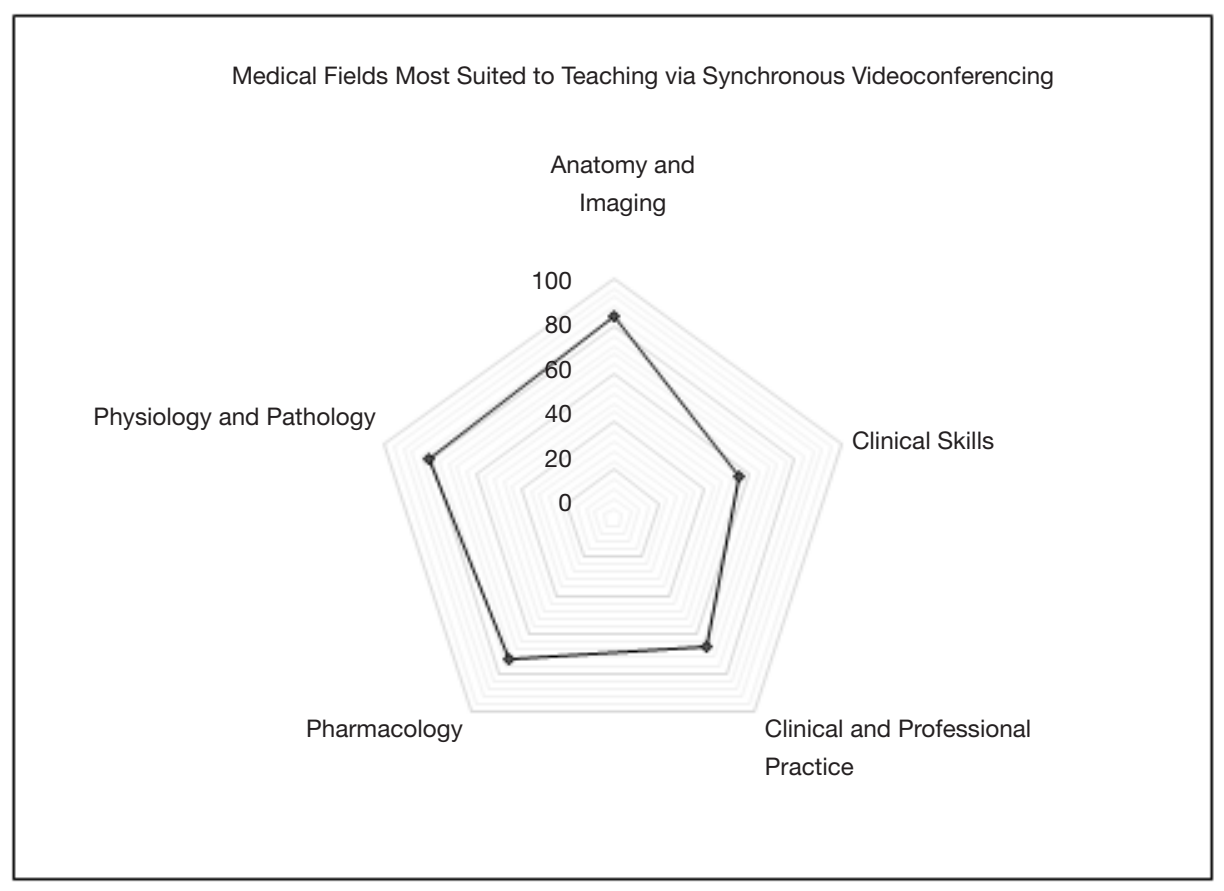

Figure 2 A radar plot showing the suitability of videoconferencing methods for the teaching of different medical subjects.

with the greatest difference in importance between medical students and educators was the ability to share notes and documents via the same platform, perhaps suggesting an overlooked area of potential support for the student.

There was an overall positive correlation between the amount participants were willing to spend per month and the maximum capacity of the videoconferencing platform, to a limit of $\$ 50$ per month. These values ranged between $\$ 10$ and $\$ 20$ for groups of less than 50 people, $\$ 25$ and $\$ 45$ for groups between 100-500, and up to $\$ 50$ for groups over 1,000 people. En masse, this data indicates that educators are willing to incur higher costs if able to reach wider audiences.

The medical fields thought to be most suited to teaching via synchronous videoconferencing were anatomy and imaging $(83.6 \%)$ and physiology and pathology $(80.4 \%)$, as shown in Figure 2. In contrast, fields associated with more substantial patient contact-clinical skills and clinical and professional practice-were thought to be less suited to online, remote teaching (55.2\% and $66 \%$ respectively).

Videoconferencing has been used as an educational tool since the 1960s for trauma, surgical procedures, and postoperative patient follow-up. Notably, in 1962, DeBakey's first demonstration of open-heart surgery in Texas was viewed by medical staff in Geneva (18). Since then, synchronous videoconferences have facilitated national and international teaching across various specialties and have been cited as a significant possible solution for the expansion of medical education in less economically developed regions (19-22). Notably, it has also been shown that there is no significant difference in national licensing exam performance between medical students who receive the majority of their lectures online through the use of synchronous videoconferencing as opposed to those that receive it in-person (23).

One institution that recently reviewed the use of videoconferencing tools for anatomy teaching found connectivity issues and restrictions surrounding the Human Tissue Act to pose a challenge to the accessibility of all normally available face-to-face materials for the students (24). Similarly, we found that $89 \%$ of those surveyed reported connectivity to be one of the most important factors in the use of videoconferencing platforms for educational purposes. This stresses that, for educational material to be used effectively, students as well as educators must have an adequate ability to access the platform. In our study, we assume satisfactory connectivity and thus no effect on the choice of platform, but do acknowledge it to be a significant possible limitation to the accessibility of online teaching via such platforms. 
Our survey found audio and video quality to be similar and sufficient across platforms and so they did not form part of our selection criteria, despite being ranked as the most important factor for those surveyed. Similarly, other features which placed highly amongst those surveyednamely, screen sharing, recording, and the ability to ask live questions-were largely present across all platforms and so did not form part of our core criteria. The weight of importance attributed by students to these more interactive features supports recent literature which shows student interaction is higher in online teaching than in face-to-face teaching (25).

All of the platforms that fit our selection criteria were deemed to fall within the parameters for cost, capacity, accessibility, safety, and maximum duration as determined by our 50 surveyed medical professionals. These platforms are comprehensively reviewed in Tables $S 1, S 2$ [currency conversions were performed using standardized rates (26)]. In order to differentiate further between them, we considered which platforms were the most cost-effective using the principles of cost-effectiveness analysis (27). We also considered any additional features the platform may have, particularly the ability to record meetings as this featured highly in importance for those surveyed.

For smaller, seminar-based teaching, this process yields BlueJeans, Blizz, Cisco Webex Meetings, Lifesize Meeting, GoToMeeting, and UberConference as similarly priced options with similar features, though Blizz and GoToMeeting are more cost-effective options due to their higher capacities. It also yields Click Meeting, Cyberlink U, EzTalks meetings Standard and Pro, EzTalks webinars, FreeConference, and VEEDEEO which sit at a higher price, but offer more features. Notably, there are also four free options that fit our criteria for smaller teaching sessions: Cisco Webex Meetings Free, ezTalks Meetings Starter, GlobalMeet, and Microsoft Teams. Of these, Microsoft Teams is the most cost-effective option due to its higher capacity and additional features.

For larger, lecture-based teaching, this process yields Amazon Chime, Blizz, and GoToMeeting as similarly priced options with similar capacities and capabilities. It also yields ezTalks Meetings Business as a more feature-rich alternative, albeit with the latter sitting at a higher price point. Micosoft Teams should be considered as a featurerich free option in this bracket which meets all of our criteria and is, therefore, the most cost-effective option for a capacity of up to 250 people.

In both cases, we excluded WebinarJam from our final selection as it runs on an annual payment which lengthens its time horizon and limits subscribers to their options should they not with to continue with remote teaching after the current pandemic and the return to normal working (28). In addition, despite meeting all other aspects of our set criteria and having a capacity of 500 people, at the time of writing, Zoom did not meet our safety standards in terms of end-to-end encryption and so was not included in our final review $(14,29)$. It has also recently become apparent that videoconferencing platforms may become the target of malicious intentions that aim to disrupt the teaching session (30). Steps can be taken to mitigate such acts including using secure links and limiting distribution of the link, password-protecting the event, ensuring participant registration and identity, muting all participants, closing chatrooms, and disabling annotations and screen sharing for all but the host.

It is important to note that more options were found for smaller capacity teaching sessions than for larger capacity teaching sessions and that beyond a capacity of 250 participants, cost was found to be the most significant barrier to videoconferencing platforms. However, it should be noted that higher-cost platforms typically provide additional features which may be of benefit to the student. Webinar options which greatly increase attendee capacity above 250 people are available but at a substantially greater cost often tailored to the individual and are, therefore, outside the scope of this article. Additional challenges to teaching via videoconferencing include ensuring student access to the technology and software sufficient to run teaching platforms as well as the delivery of content at an appropriate time across different time zones.

This said, the extensive range of different platforms provide for a multitude of teaching methods with various additional features which add a greater variety and depth of communication that would otherwise not be possible. In addition, the use of recording methods further adds to remote learning, allowing students to revisit teaching content that would otherwise only be delivered on a one-off basis. The importance of this capability to student bodies is well described in the literature (31).

The main drawback of our study is that the survey relies entirely on self-reporting with a relatively small sample population (50 people). Hence, though we assume that the participants completed the survey in an honest and well-thought-out manner, the integrity of our results does lie with the honesty and accuracy of those surveyed. In addition, all respondents are from a medical background and 
so our results may not be generalizable to other educational fields or teaching styles. We also recognize that it is essential to consider the innate advantages and drawbacks of each platform, such that an individual compromise must be reached depending on each user's needs.

In times of social isolation, videoconferencing should be seen as a powerful tool which enables educators to continue the delivery of their teaching to students worldwide and which works to ensure a physical distance whilst maintaining social connectivity.

\section{Acknowledgments}

Funding: None.

\section{Footnote}

Conflicts of Interest: All authors have completed the ICMJE uniform disclosure form (available at http://dx.doi. org/10.21037/qims-20-714). KM serves as an unpaid editorial board member of Quantitative Imaging in Medicine and Surgery. The authors have no other conflicts of interest to declare.

Ethical Statement: This service evaluation was approved by the institutional review board (reference number 2835). Consent was obtained from participants before commencement of the surveys.

Open Access Statement: This is an Open Access article distributed in accordance with the Creative Commons Attribution-NonCommercial-NoDerivs 4.0 International License (CC BY-NC-ND 4.0), which permits the noncommercial replication and distribution of the article with the strict proviso that no changes or edits are made and the original work is properly cited (including links to both the formal publication through the relevant DOI and the license). See: https://creativecommons.org/licenses/by-nc-nd/4.0/.

\section{References}

1. World Health Organisation. Coronavirus disease 2019 (COVID-19) Situation Report - 82 [Internet]. Geneva: WHO; 2020. Accessed Apr 30 2020. Available online: https://www.who.int/docs/default-source/coronaviruse/ situation-reports/20200411-sitrep-82-covid-19. pdf?sfvrsn=74a5d $15 \_2$

2. Ferguson NM, Laydon D, Nedjati-Gilani G, Imai G,
Ainslie N, Baguelin K, Bhatia M, Boonyasiri S, Cucunubá A, Cuomo-Dannenburg Z, Dighe G, Dorigatti A, Fu I, Gaythorpe H, Green K, Hamlet W, Hinsley A, Okell W, Van Elsland LC, Thompson S, Verity H, Volz R, Wang E, Wang H, Wang Y, Walker PGT, Walker C, Winskill P, Whittaker C, Donnelly CA, Riley S, Azra GC. Impact of non-pharmaceutical interventions (NPIs) to reduce COVID-19 mortality and healthcare demand [Internet]. London: Imperial College London COVID-19 Response Team; 2020. Accessed Apr 30 2020. Available online: https://www.imperial.ac.uk/media/imperial-college/ medicine/mrc-gida/2020-03-16-COVID19-Report-9.pdf

3. Anderson RM, Heesterbeek H, Klinkenberg D, Hollingsworth TD. How will country-based mitigation measures influence the course of the COVID-19 epidemic? Lancet 2020;395:931-4.

4. Wilder-Smith A, Freedman DO. Isolation, quarantine, social distancing and community containment: pivotal role for old-style public health measures in the novel coronavirus (2019-nCoV) outbreak. J Travel Med 2020;27:taaa020.

5. Ferguson NM, Cummings DA, Cauchemez S, Fraser C, Riley S, Meeyai A, Iamsirithaworn S, Burke DS. Strategies for containing an emerging influenza pandemic in Southeast Asia. Nature 2005;437:209-14.

6. Ferguson NM, Cummings DAT, Fraser C, Cajka JC, Cooley PC, Burke DS. Strategies for mitigating an influenza pandemic. Nature 2006;442:448-52.

7. Hatchett RJ, Mecher CE, Lipsitch M. Public health interventions and epidemic intensity during the 1918 influenza pandemic. Proc Natl Acad Sci U S A 2007;104:7582-7.

8. Rashid H, Ridda I, King C, Begun M, Tekin H, Wood JG, Booy R. Evidence compendium and advice on social distancing and other related measures for response to an influenza pandemic. Paediatr Respir Rev 2015;16:119-26.

9. Reluga TC. Game Theory of Social Distancing in Response to an Epidemic. PLoS Comput Biol 2010;6:e1000793.

10. Kelso JK, Milne GJ, Kelly H. Simulation suggests that rapid activation of social distancing can arrest epidemic development due to a novel strain of influenza. BMC Public Health 2009;9:117.

11. Prem K, Liu Y, Russell TW, Kucharski AJ, Eggo RM, Davies N; Centre for the Mathematical Modelling of Infectious Diseases COVID-19 Working Group, Jit $\mathrm{M}, \mathrm{Klepac}$ P. The effect of control strategies to reduce social mixing on outcomes of the COVID-19 epidemic in 
Wuhan, China: a modelling study. Lancet Public Health 2020;5:e261-e270. Erratum in: Correction to Lancet Public Health 2020; 5; e261-70. Lancet Public Health. 2020 May;5(5):e260.

12. Chow R. A citizen's thoughts about COVID-19. Lancet 2020;395:e65.

13. United Nations Educational, Scientific and Cultural Organization. COVID-19 Educational Disruption and Response. Geneva: UNESCO, 2020.

14. Keesara S, Jonas A, Schulman K. Covid-19 and Health Care's Digital Revolution. N Engl J Med 2020;382:e82

15. General Medical Council. Coronavirus information and advice: Information for medical students. London: GMC; 2020. Accessed Apr 30 2020. Available online: https://www. gmc-uk.org/news/news-archive/coronavirus-informationand-advice/information-for-medical-students

16. Oxford English Dictionary. videoconferencing, adj.: Oxford English Dictionary. Oxford: Oxford University Press, 2020. Accessed Apr 302020.

17. World Health Organisation. 2015 Global Survey on Health Technology Assessment by National Authorities. Geneva: WHO, 2015.

18. Augestad KM, Lindsetmo RO. Overcoming Distance: Video-Conferencing as a Clinical and Educational Tool Among Surgeons. World J Surg 2009;33:1356-65.

19. Cook A, Pippi Salle JL, Reid J, Chow KF, Kuan J, Razvi H, Farhat WA, Bagli DJ, Khoury AE. Prospective Evaluation of Remote, Interactive Videoconferencing to Enhance Urology Resident Education: The Genitourinary Teleteaching Initiative. J Urol 2005;174:1958-60.

20. Hadley GP, Mars M. Postgraduate medical education in paediatric surgery: videoconferencing-a possible solution for Africa? Pediatr Surg Int 2008;24:223-6.

21. Spitzer RF, Kives S, Ornstein M, Caccia N, Stephens D, Flood C, Allen LM. Videoconferencing for Resident Teaching of Subspecialty Topics: The Pediatric and Adolescent Gynecology Experience at the Hospital for

Cite this article as: Sidpra J, Gaier C, Reddy N, Kumar N, Mirsky D, Mankad K. Sustaining education in the age of COVID-19: a survey of synchronous web-based platforms. Quant Imaging Med Surg 2020;10(7):1422-1427. doi: 10.21037/ qims-20-714
Sick Children. J Pediatr Adolesc Gynecol 2008;21:343-6.

22. Kiwanuka JK, Ttendo SS, Eromo E, Joseph SE, Duan ME, Haastrup AA, Baker K, Firth PG. Synchronous distance anesthesia education by Internet videoconference between Uganda and the United States. J Clin Anesth 2015;27:499-503.

23. Hortos K, Sefcik D, Wilson SG, McDaniel JT, Zemper E. Synchronous Videoconferencing: Impact on Achievement of Medical Students. Teach Learn Med 2013;25:211-5.

24. Allsop S, Hollifeld M, Huppler L, Baumgardt DR, van Eker D, Spear M, Fuller C. Using videoconferencing to deliver anatomy teaching to medical students on clinical placements. Translational Research in Anatomy 2020;19:100059.

25. Kay D, Pasarica M. Using technology to increase student (and faculty satisfaction with) engagement in medical education. Adv Physiol Educ 2019;43:408-13.

26. XE. XE Currency Converter - Live Rates. 2020 [accessed Apr 30 2020]. Available online: https://www.xe.com/ currencyconverter/

27. Detsky AS, Naglie IG. A clinician's guide to costeffectiveness analysis. Ann Intern Med 1990;113:147-54.

28. Ebert RJ, Piehl D. Time Horizon: A Concept for Management. Calif Manage Rev 1973;15:35-41.

29. Paul K. 'Zoom is malware': why experts worry about the video conferencing platform [Internet]. The Guardian. 2020. Accessed Apr 30 2020. Available online: https:// www.theguardian.com/technology/2020/apr/02/zoomtechnology-security-coronavirus-video-conferencing

30. Wakefield J. Coronavirus: Racist “zoombombing” at virtual synagogue. BBC News. 2020. Accessed Apr 30 2020. Available online: https://www.bbc.co.uk/news/ technology-52105209

31. Wynter L, Burgess A, Kalman E, Heron JE, Bleasel J. Medical students: what educational resources are they using? BMC Med Educ 2019;19:36. 
Table S1 A summary of the available platforms meeting our selection criteria for smaller, seminar-based teaching

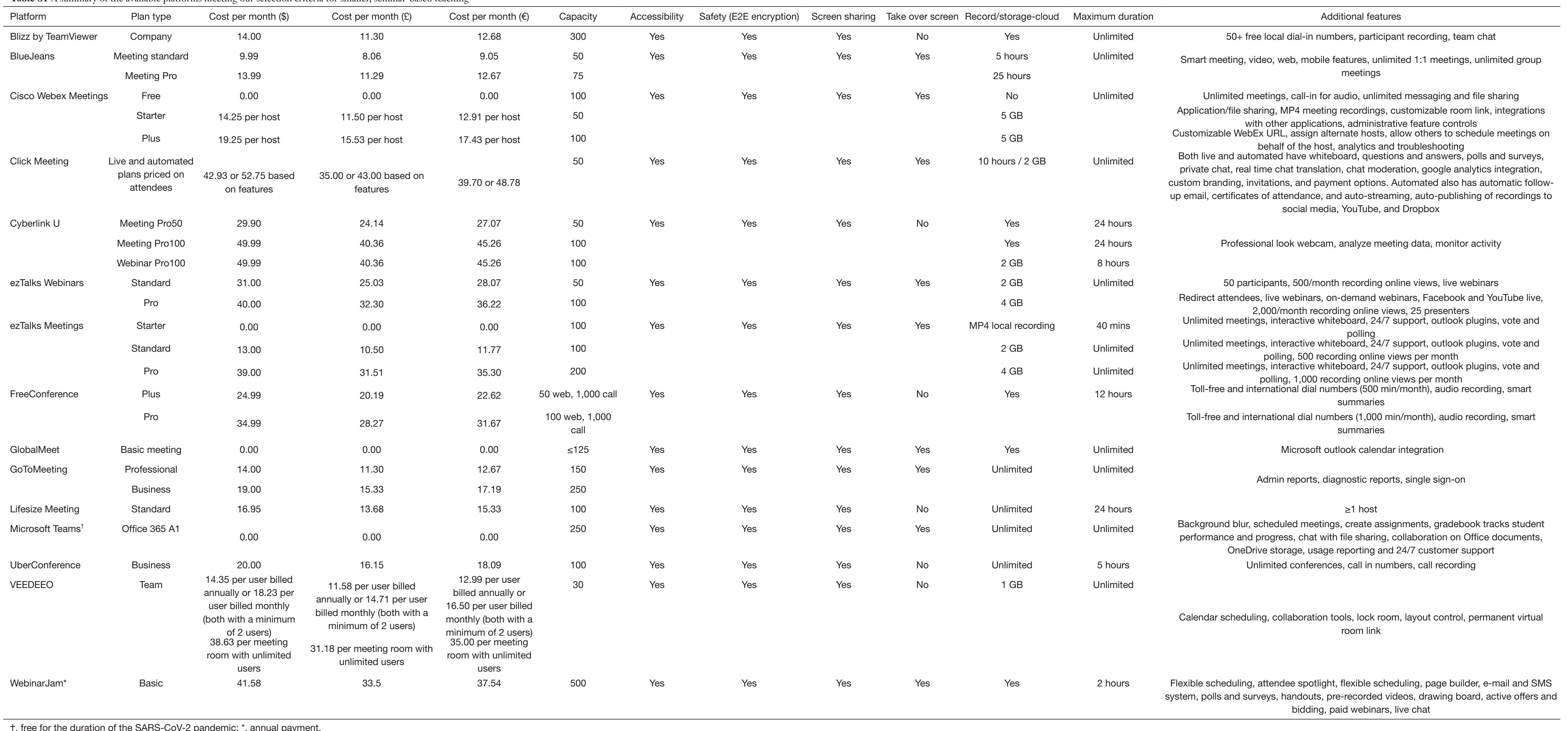


Table S2 A summary of web-based synchronous videoconferencing platforms meeting our selection criteria

\begin{tabular}{|c|c|c|c|c|c|c|c|c|c|c|c|c|}
\hline Platform & Plan type & Cost per month (\$) & Cost per month (£) & Cost per month $(€)$ & Capacity & Accessibility & Safety (E2E encryption) & $\begin{array}{l}\text { Screen } \\
\text { sharing }\end{array}$ & $\begin{array}{l}\text { Take over } \\
\text { screen }\end{array}$ & $\begin{array}{l}\text { Record/storage- } \\
\text { cloud }\end{array}$ & $\begin{array}{l}\text { Maximum duration } \\
\text { (hours) }\end{array}$ & Additional features \\
\hline Amazon Chime & Pro & 15.00 per user & 12.11 per user & 13.57 per user & 250 & Multi-platform & Yes & Yes & Yes & Yes & 24 & $\begin{array}{c}\text { Lock meetings, chat rooms, personalize link, schedule meetings, assign } \\
\text { delegates }\end{array}$ \\
\hline $\begin{array}{l}\text { Blizz by } \\
\text { TeamViewer }\end{array}$ & Company & 14.00 & 11.3 & 12.67 & 300 & Multi-platform & Yes & Yes & No & Yes & Unlimited & $50+$ free local dial-in numbers, participant recordings, team chat \\
\hline ezTalks Meetings & Business & 50.00 & 40.31 & 45.28 & 300 & Multi-platform & Yes & Yes & Yes & $10 \mathrm{~GB}$ & Unlimited & $\begin{array}{l}\text { Unlimited meetings, team chat, interactive whiteboard, } 24 / 7 \text { support, } \\
\text { outlook plugins, vote and polling, } 300 \text { recording online views per month }\end{array}$ \\
\hline GoToMeeting & Business & 19.00 & 15.31 & 17.20 & 250 & Multi-platform & Yes & Yes & Yes & Unlimited & Unlimited & Admin reports, chat room, diagnostic reports, single sign-on \\
\hline Microsoft Teams ${ }^{\dagger}$ & Office $365 \mathrm{~A} 1$ & 0.00 & 0.00 & 0.00 & 250 & Multi-platform & Yes & Yes & Yes & Yes & Unlimited & $\begin{array}{l}\text { Background blur, scheduled meetings, create assignments, gradebook } \\
\text { tracks student performance and progress, chat with file sharing, } \\
\text { collaboration on Office documents, OneDrive storage, usage reporting and } \\
24 / 7 \text { customer support }\end{array}$ \\
\hline \multirow[t]{2}{*}{ WebinarJam* } & Basic & 41.58 & 33.46 & 37.58 & 500 & Multi-platform & Yes & Yes & Yes & Yes & 2 & \multirow{2}{*}{$\begin{array}{l}\text { Flexible scheduling, attendee spotilight, flexible scheduling, page builder, } \\
\text { e-mail and SMS system, polls and surveys, handouts, pre-recorded } \\
\text { videos, drawing board, active offers and bidding, paid webinars, live chat }\end{array}$} \\
\hline & Professional & 58.25 & 46.96 & 52.74 & 2,000 & Multi-platform & Yes & Yes & Yes & Yes & 3 & \\
\hline
\end{tabular}

